\section{A new dental school in Cairns}

\author{
A. D. Walmsley ${ }^{1}$
}

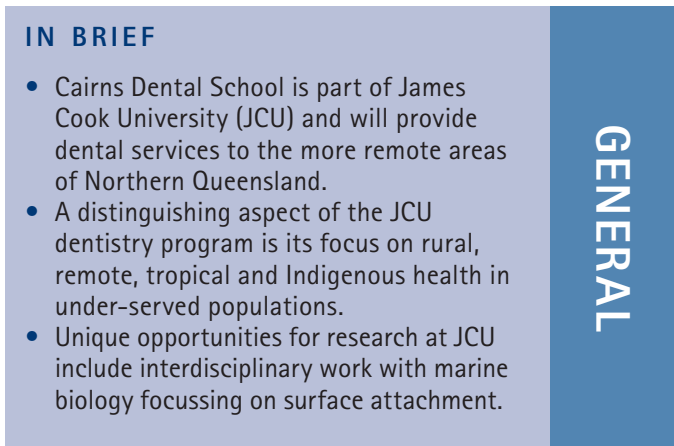

Starting a new school is a challenge, especially in the present economic climate, but that is the situation facing several schools in Australia. Due to the shortage of dental manpower, especially in the more remote areas of Australia, the Federal Government has provided funds to increase the number of dentists in training. One of the areas chosen for a new dental school was Cairns, Northern Queensland and the administration of the new school is under the auspices of the James Cook University (JCU). The Main JCU campus is at Townsville which is $340 \mathrm{~km}$ (212 miles) away and about four hours' driving distance (Fig. 1). The Faculty of Medicine, Health and Molecular Sciences offers many health professional programs at both campuses, including Medicine, Physiotherapy and Pharmacy at the Townsville Campus and Dentistry and Nursing in Cairns (Fig. 2).

Dentistry is suited to Cairns as it has the ability to reach out and provide dental cover to some far away places. Distances are large and in many areas it is not possible to provide routine treatment for the population. For instance the Torres Straits, Mt Isa and even Rockhampton, names that may well be unfamiliar to UK dentists, provide great challenges to the provision of primary care services to the local population. You just need to look at the map of Northern Queensland to appreciate the difficulties. In many cases it is just not possible to access dental treatment and even in metropolitan centres such as Cairns accessing specialist services which includes the majority of the restorative specialties is very difficult. A flight to Sydney or Brisbane becomes one of the few options available.

James Cook University, Cairns, has accepted its second year of 67 dental students, many of whom are indigenous to the northern part of Queensland. For many of these students, Cairns is a big city and they see themselves returning to the quieter

\footnotetext{
Professor of Restorative Dentistry, School of Dentistry, The University of Birmingham, St Chad's Queensway, Birmingham, B4 6NN

Correspondence to: Professor Damien Walmsley Email: a.d.walmsley@bham.ac.uk
}

\section{Refereed Paper}

Accepted 3 November 2009

DOI: $10.1038 /$ sj.bdj.2009.1111

${ }^{\circledR}$ British Dental Journal 2009; 207: 545-546

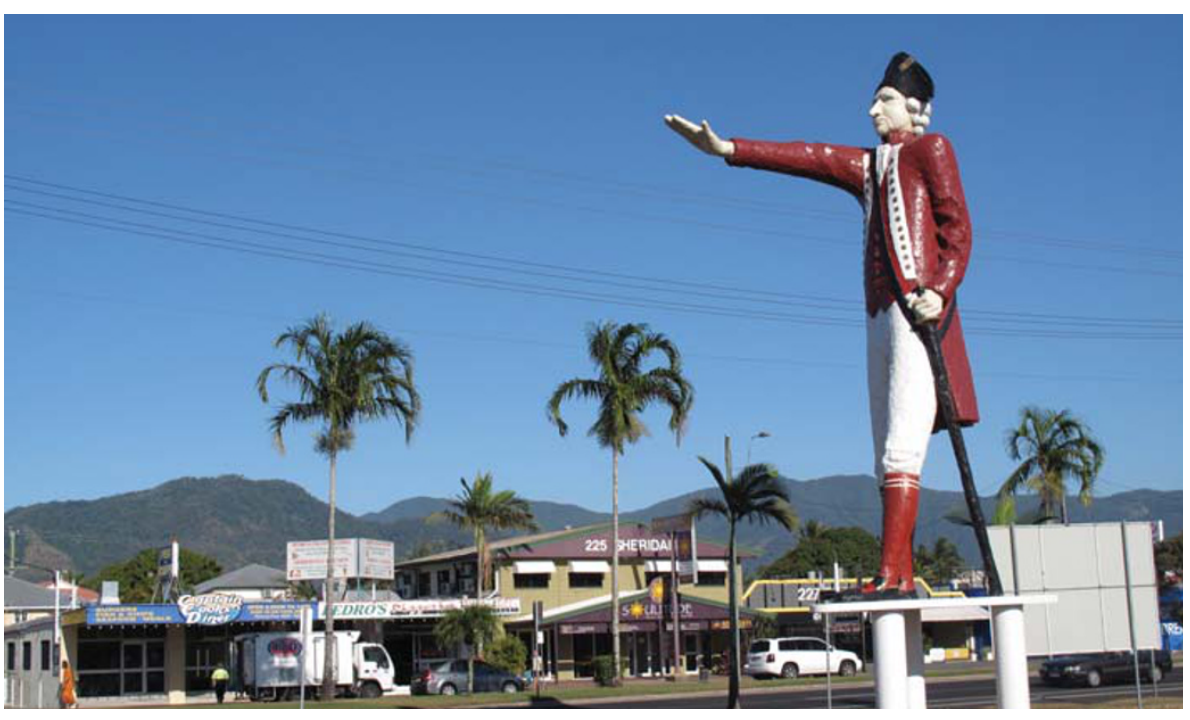

Fig. 1 The James Cook Highway that passes through Cairns

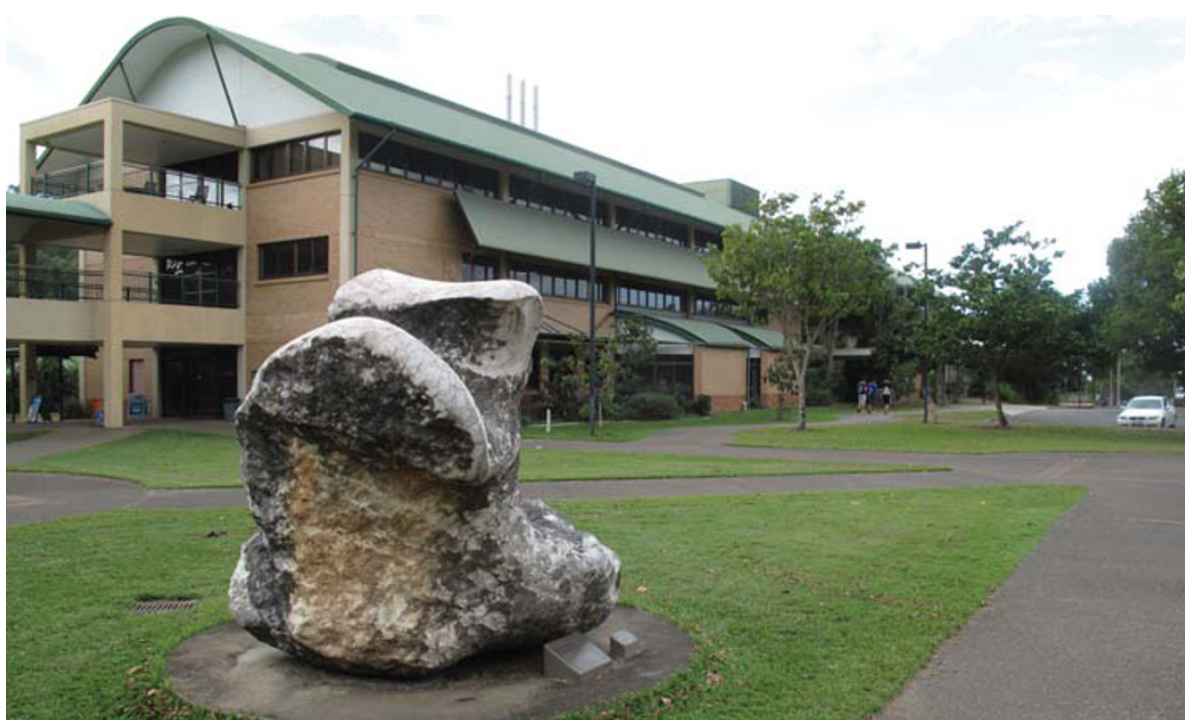

Fig. 2 James Cook University, Cairns Campus 
rural areas from where they originated. The course has thrown up many challenges but Professor Sandham (Fig. 3) is a resourceful person and while the school remains under construction, with completion later next year, there is already a fully-functional simulation laboratory and prosthodontic laboratory facilities. The new School is located in the tropics, and there is a distinct tropical feel in the unique 'Dentistry Village' where students are able to participate in self-directed learning and organise themselves into small learning groups or 'home groups', each with its own 'home room'. The Village includes an all-weather outdoor community area where home groups can congregate and discuss their work. It provides a relaxed learning environment for the students, which they see as their 'own' area. (Fig 4).

The course is student centred and will be spread over five years with students receiving modules in a range of subject. This will include subjects such as Communication Skills and Introduction to Dental Science in their first year of study to integrating more clinically based modules as the course progresses. The basic clinical training and teaching will take place at the base site at the JCU campus at Cairns with the final year comprised mainly of outreach placements throughout Northern Queensland. Dentistry is a unique health subject and the teaching of dental students requires one-to-one training in their early years. The school recognises that it is essential that such clinical skills be imparted to the students in their formative years. Once the concept of whole patient care is understood then they are in a position to enter into the community based clinics of Queensland Health.

Professor Sandham has also been able to call upon his extensive network of colleagues and the strong connection with the University of Birmingham, School of Dentistry has brought about close links between the two schools. Several staff have been invited out to either advise or participate in the undergraduate curriculum. Andrew is well known to many in the West Midlands having been an

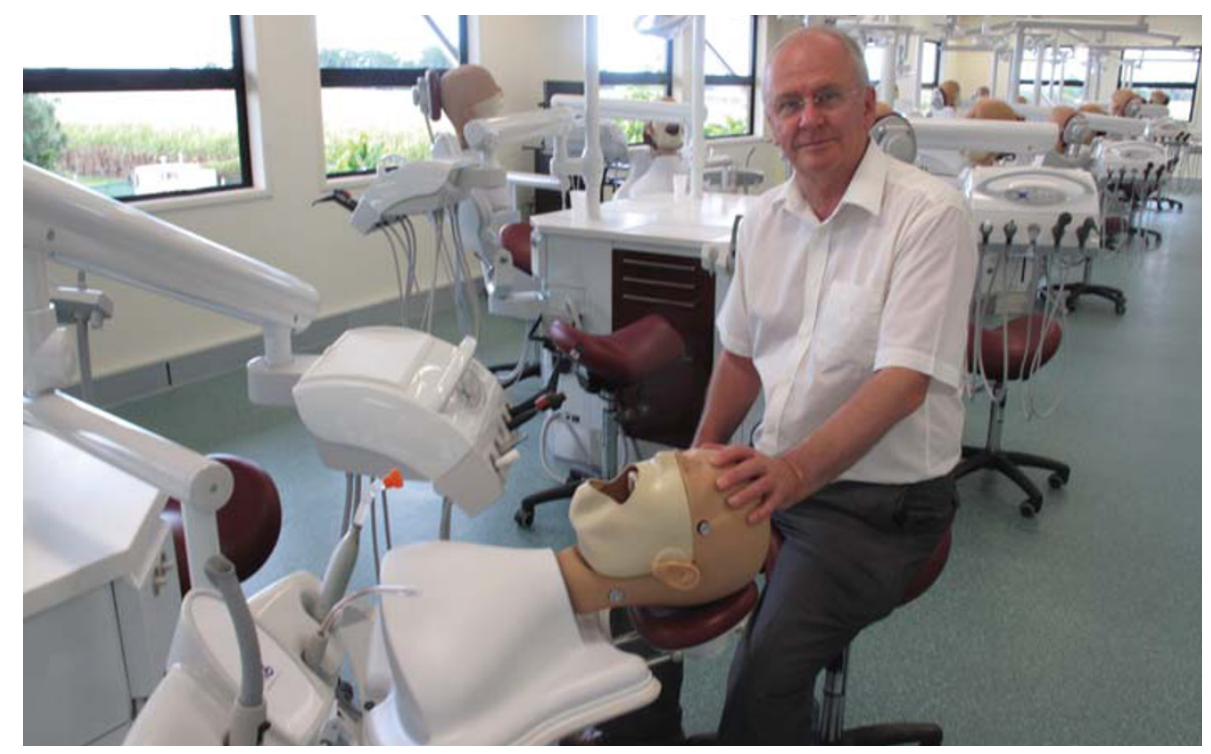

Fig. 3 The Dean of Cairns, Andrew Sandham

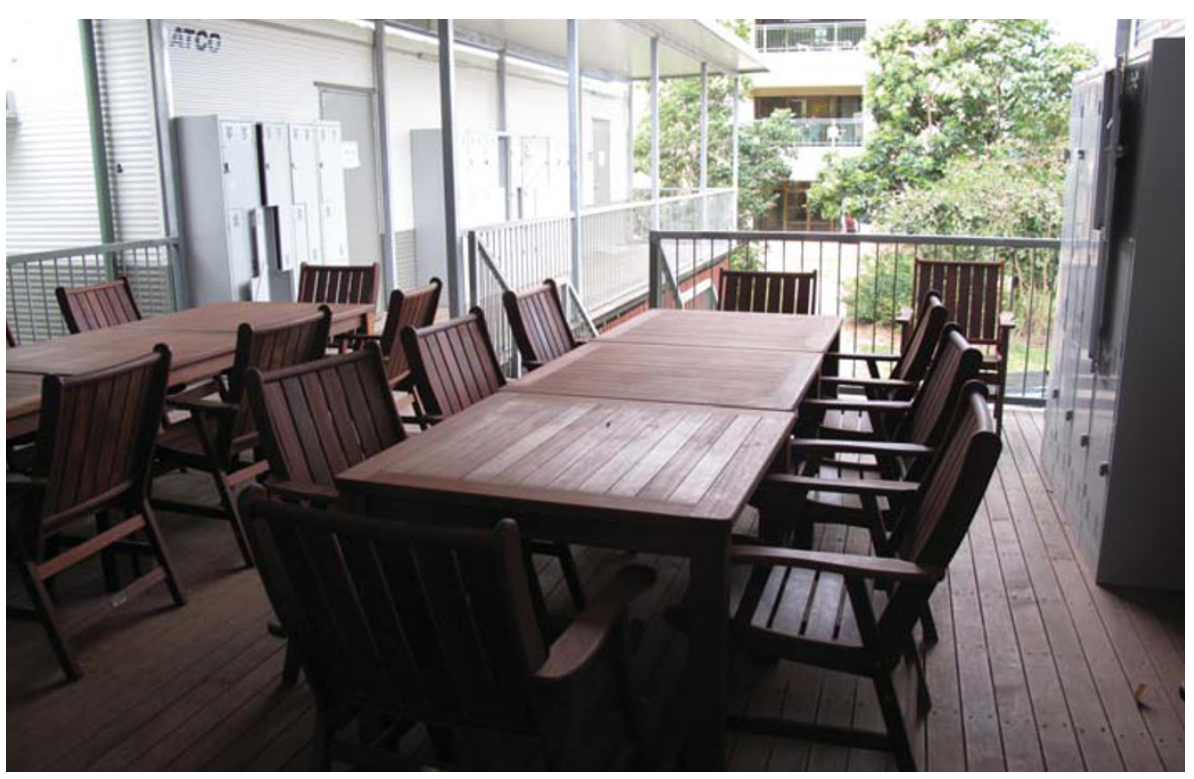

Fig. 4 Part of the dentistry student village

Orthodontic Consultant in Birmingham and Coventry. The recruitment of staff is taking place and already the school is fortunate in having made several key appointments. There is strong support from the basic scientists who have assisted in the development of the course but the biggest challenge is setting up outreach centres for the students.

The university has a strong research base in the area of marine biology and dentistry has seen an opportunity of forming an interdisciplinary research group that focuses on surfaces. The two environments, the sea and the mouth are not too dissimilar and whether it is attachment to a titanium surface or a coral reef, such research may bring out interesting cross over results. The dentistry project at Cairns is an exciting one and it will be watched closely to see if their successes will assist others in the education of dentists.

The author wishes to thank Professor Andrew Sandham, Rose Hogan (Education \& Curriculum Officer - Dentistry) and all the dental school staff and students for allowing him the opportunity to visit and comment on the new dental School facilities at the James Cook University, Cairns. 